\title{
A EXPERIMENTAÇÃO DO ESPAÇO PARA O DESIGN 0 processo de desenvolvimento da disciplina acadêmica de linguagem e expres- são espacial no curso de design
}

Nathália Feitosa Barbosa

Juliana Michaello Macedo Dias

\begin{abstract}
Resumo: Compreende-se o espaço como uma peça importante para projetação e desenvolvimento do trabalho do designer, que deve se ter uma consideração de relevância desde a universidade. Assimila-se em vista disso, que ao propor a montagem da disciplina a partir de práticas de percepção de espaços, nas quais os alunos são levados a experimentá-los a partir das suas percepções individuais, a disciplina oferece uma abertura para que diferentes experiências surjam e sejam testadas ao longo da mesma. 0 trabalho vem por meio deste, apresentar as competências possíveis a serem desenvolvidas para que se possa acarretar impactos através do design, de resoluções inovadoras e proveitosas.
\end{abstract}

Palavras-chave: Design, Espaço, Desenvolvimento, Disciplina Acadêmica.

\section{INTRODUÇÃO}

O espaço, como concepção física, diz respeito ao meio que nos envolve. Conjuntamente, umas das mais importantes preocupações do design é o modo que a criação se relaciona com o usuário e permite o uso mais adequado dos espaços, fazendo-se assim presente como mediador entre o urbano e o homem. Isso fica claro na Bauhaus, primeira escola de design criada por Walter Gropius na Alemanha, onde tudo está em função dos espaços habitáveis.

A experimentação do espaço depende da nossa capacidade de nos sentir olhados, isto é, da nossa sensibilidade de ver o não visto, ou o não visível, de sentir o que não está ali na sua fisicalidade ou visibilidade para ser propriamente sentido. Isso se constitui um grande impasse na relação entre aquele que vê ou experimenta e aquilo que é visto ou experimentado. (DIDI-HUBERMAN, 2010).

Tanto o corpo quanto o espaço, são noções de difícil definição se pensarmos apenas do ponto de vista teórico, não é raro nos depararmos com projetos e intervenções que se encontram distantes de uma perspectiva espacial humanizada, que muitas vezes não as tocam e não se encaixam. Sendo deste modo a aproximação com os espaços nos parece ser um fator determinante para evidenciar o caráter vivido dos espaços e garantir uma maior proximidade tanto dos designers quanto dos usuários com os mesmos.

Ao imergir no processo da disciplina acadêmica de Linguagem e Expressão Espacial (LEE), o estudo tem por objetivo analisar as atividades propostas aos alunos que cumpriram a matéria durante o período acadêmico de 2016.2 e 2017.1, que serão chamadas de turma A e B respectivamente. Essas atividades que, em seu objetivo central, se propõe a coloca-los em diversas situações de experimentação, tanto do próprio corpo 
e do corpo dos colegas de classe, como também a relação entre o corpo e o espaço.

\section{DESENVOLVIMENTO}

A disciplina tem como ementa o estudo e desenvolvimento de composições tridimensionais, com o objetivo de desenvolver no aluno a capacidade de perceber e interpretar o espaço através de experimentações corpóreo-sensoriais, incentivar o aluno a experimentar meios de expressão de ideias através de trabalhos espaciais em diversas escalas como também desenvolver no aluno a percepção do processo criativo como atividade contínua de experimentação e discussão conceitual. No entanto, esse artigo tem o objetivo de apresentar as competências possíveis a serem desenvolvidas para que se possa acarretar impactos através do design, de resoluções inovadoras e proveitosas.

\section{O Corpo}

Por ser um elemento tão presente e participativo no cotidiano, o corpo é muitas vezes tido como algo que passa despercebido, paralelamente em que é o agente protagonista dessas mesmas vivências cotidianas, onde através do corpo é possível expressar personalidades, valores culturais, humores, etc.

Nos primeiros momentos da disciplina, é estimulado aos alunos perceber a existência do próprio corpo no espaço através das suas experiências e assim, a partir de suas próprias falas, tomar consciência dos movimentos e gestos exercidos por eles mesmos todos os dias, assimilando suas corpografias.

A corpografia é uma cartografia corporal (ou corpo-cartografia), ou seja, parte da hipótese de que a experiência urbana fica inscrita, em diversas escalas de temporalidade, no próprio corpo daquele que a experimenta, e dessa forma também o define, mesmo que involuntariamente. (BERENSTEIN JACQUES, 2008).

Para a realização desta etapa, é feita em primeira instância uma discussão de texto sobre o assunto, gerando diversas reflexões pessoais, seguida pelo primeiro momento de experimentação onde exercem suas errâncias, que segundo Berenstein Jacques (2008) "É a prática que designa a própria experiência urbana e, em particular, a experiência corporal da cidade.".

Após exercitarem uma auto percepção dos seus corpos e das particularidades que carregam junto a ele, são feitas atividades corpóreas em duplas permutando as experiências corporais para perceber e retratar o modo singular como cada corpo expressa sua corporeidade.

\section{0 corpo da cidade}

Geralmente concebido como o cenário onde a vida se desenvolve, o espaço, como dimensão das ações que nele são exercidas é, simultaneamente ao corpo, negligenciado principalmente por aqueles que o percorrem diariamente tornando-o como apenas um caminho para chegar ao destino que desejam.

Os elementos constituintes dos corpos se estendem a outras dimensões da realidade. Os espaços urbanos são constituídos pelas pessoas, arquitetura, ruas e calçadas que conjuntamente compõem o corpo da cidade e trazem o questionamento da relação entre o urbanismo e o corpo, e posteriormente como os mesmos interagem.

O estudo corpográfico pode ser interessante para se compreender as pré-existências corporais resultantes da experiência do espaço, para se apreender as pré-existências espaciais registradas no próprio corpo através das experiências urbanas. (BERENSTEIN JACQUES, 2008) 
Seguindo essa linha de pensamento, é nesta etapa que se terá um contato direto com o corpo da cidade a partir de uma experiência de deriva, que seria "uma apropriação do espaço urbano pelo pedestre através da ação do andar sem rumo." (JACQUES, 2004).

No desenrolar desta etapa da disciplina, os alunos debatem e discutem as possibilidades de lugares a serem experimentados e escolhem por meio de votação o local onde se passará a deriva urbana feita por eles, para posteriormente em sala relatarem o que foi visto e percebido através da errância voluntária pelas ruas.

\section{Intervenções Espaciais}

Após os estágios do conhecer, explorar e experimentar é imprescindível dar continuidade ao que vêm sido apanhado e materializar, traduzindo para a prática os sentimentos, de modo a direcionar e estabelecer o que foi o estágio da experimentação através das intervenções espaciais.
As intervenções temporárias são aqui entendidas como as ações que se movem no âmbito do transitório, do pequeno, das relações sociais, que envolvem a participação, ação, interação e subversão, e que são motivadas por situações existentes e particulares do contexto urbano, em contraposição ao projeto estandardizado, caro, permanente e de grande escala, o "grande evento". Diferentemente dos usos cotidianos na cidade, as intervenções são açõ̃es que contém a intenção de transformação do espaço [...].
(SANSÃO, 2012, p. 70).

Os alunos se agrupam em pequenos grupos, utilizando um critério definido por eles, de acordo com o que acreditam que melhor irá complementar as experiências individuais que a partir desse momento serão desenvolvidas conjuntamente para se alcançar a intervenção espacial.

Para dar início a concepção do ato é preciso dar algumas diretrizes do que se deve dar atenção para uma boa repercussão da intervenção, como a temporalidade, o espaço a ser utilizado, o que pretende ser passado e quem se pretende atingir. Tendo esse direcionamento os alunos possuem total autonomia na escolha de materiais, propostas e produção.

\section{RESULTADOS E DISCUSSÕES}

Acompanhando o processo da disciplina primeiramente como aluna e posteriormente como monitora, pude perceber algumas diferenças no andamento da disciplina, relacionadas às dinâmicas particulares de cada turma, que serão brevemente relatadas aqui.

Na primeira etapa que corresponde ao corpo, os alunos reconheceram a linguagem de seus corpos e descreveram essa fala nomeando com uma palavra que conseguisse transcrevê-la devidamente. Em seguida formaram duplas para dar continuação a atividade.

A turma A foi unida pelos opostos, e precisaram instruir o par a agir da forma como seu corpo se expressa. Foi notável para eles a dificuldade em deslocar-se de seus âmbitos corporais para um totalmente novo e divergente, principalmente por ser uma atuação das formas gestuais do outro, e precisar passar para os espectadores os sentimentos que designavam a palavra escolhida.

Enquanto a turma B foi agrupada aleatoriamente, e deveriam criar um objeto que se relacionasse com três palavras escolhidas para descrever suas corporeidades. A 
partir das palavras da dupla, esse objeto deveria utilizar o corpo como suporte, eles se atentaram a perceber texturas, cores e formatos que fossem colaborativos com os sentimentos que queriam passar.

Foram produzidas por eles fotografias para se pensar sobre como transmitir sensações visualmente. Por fim, os objetos foram criados em sala, como na figura 1, e testados no corpo do colega que iria utilizá-lo, como na figura 2, foi notado por eles que quando testado em corpos diferentes o objeto reproduzia efeitos diferentes.

Figura 1 - Montagem dos objetos em sala Fonte: Elaborado pelo autor, com base na pesquisa realizada, 2017.

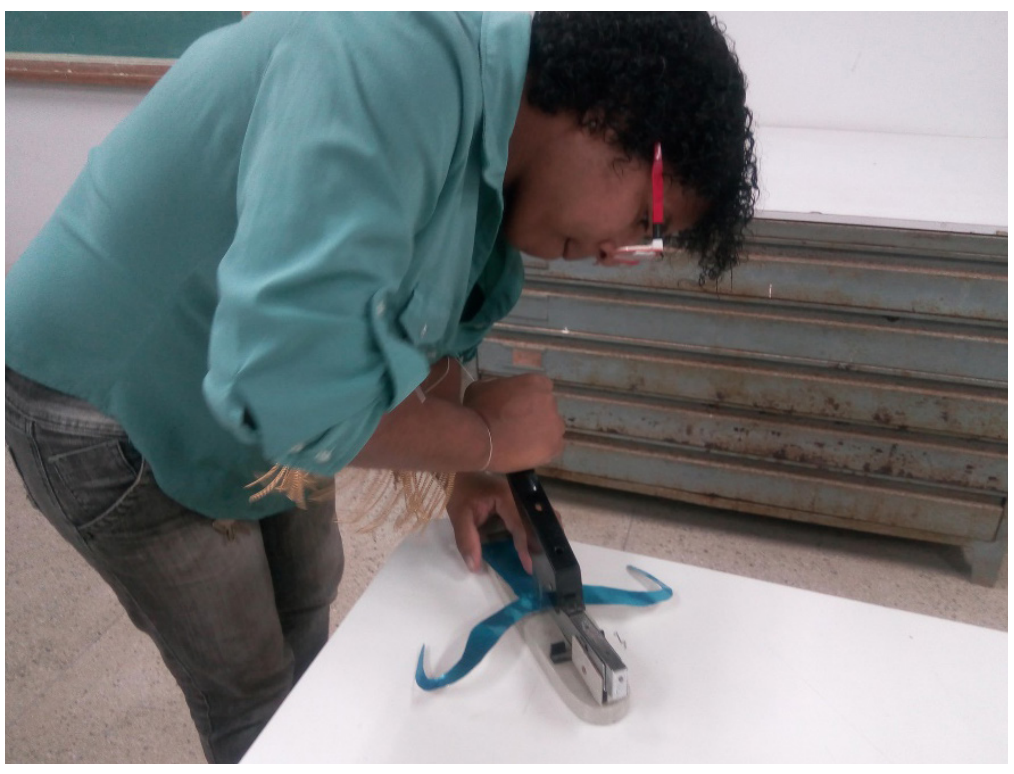

Figura 2 - Teste dos objetos no corpo da dupla Fonte: Elaborado pelo autor, com base na pesquisa realizada, 2017.

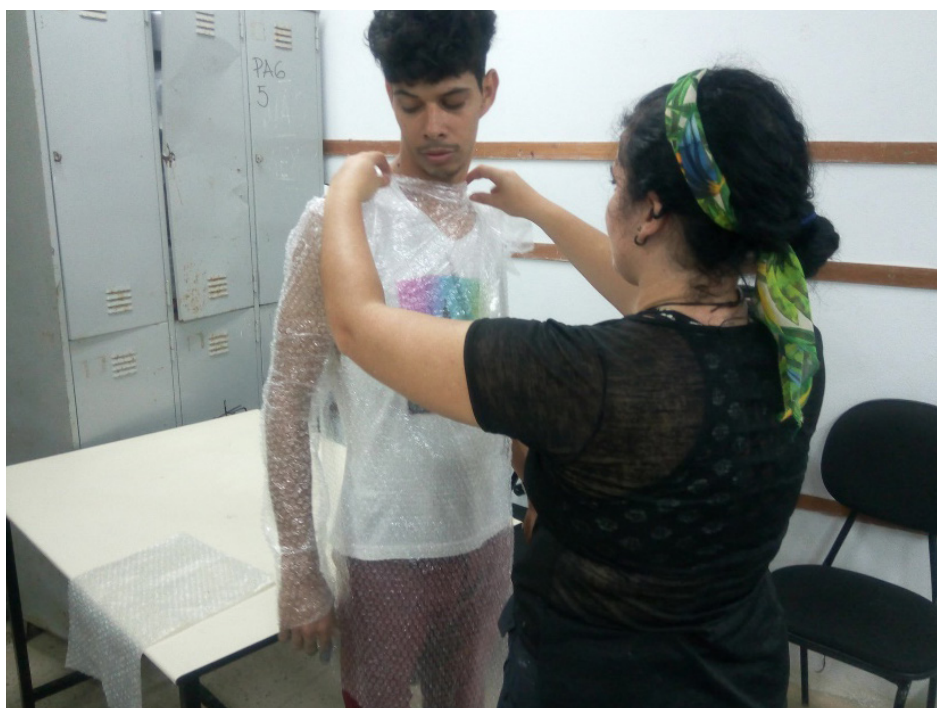

Na segunda etapa que se refere ao corpo da cidade, em ambas as turmas, os locais foram sugeridos pelos alunos que argumentaram os prós e os contras de ocorrer à experiência da deriva nesses locais, e logo após fizeram votação para defini-lo. Enquanto a turma A escolheu o Mercado da Produção de Maceió e a turma B a Praia da Avenida, também na cidade de Maceió.

As duas turmas passaram previamente por um processo de expectativas das concepções sobre o rumo que eles acreditavam que seria tomado durante as derivas voluntárias, diante disto foi solicitado que adotassem uma palavra que resumisse essas expectativas. 
Para a turma A foi criada uma representação espacial da expectativa acerca do mercado, conforme figura 3, podendo ser em formato de foto ou vídeo junto a suas explicações sobre o que estava sendo representado. Os trabalhos foram importantes para conduzir as missões incorporadas nas andanças a serem feitas.

Figura 3 - Objeto representativo da expectativa de uma das alunas Fonte: Elaborado pelo autor, com base na pesquisa realizada, 2017.

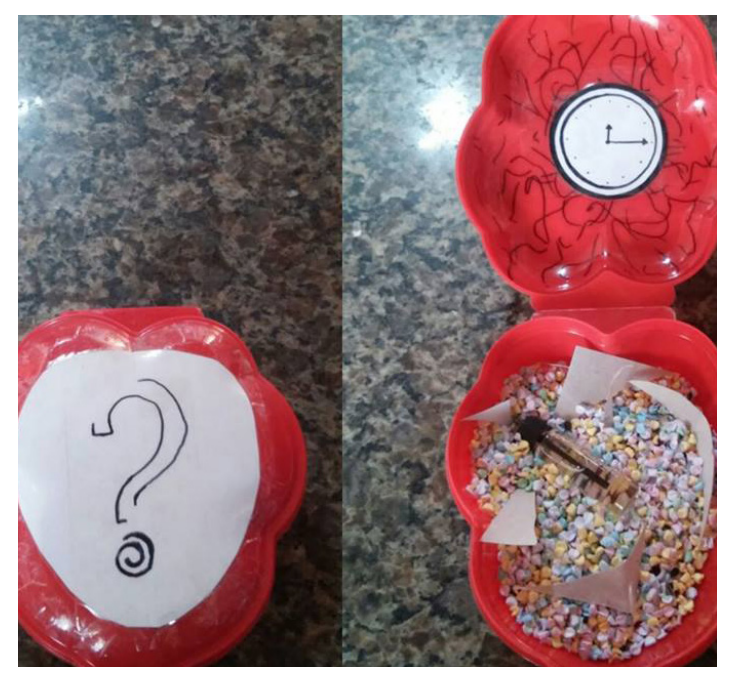

Para a turma B, a palavra foi proveniente das três palavras da atividade anterior que se referenciavam ao corpo do colega, sendo escolhido a que se pareceu mais marcante para eles, encaminhando para a missão da andança, finalizando assim com a palavra-expectativa.

Por fim, tendo a experiência de deriva concluída, como tanto na turma A como na B cada aluno dispôs de uma tarefa diferente, foi perceptível como cada relato se parecia tão diferente do outro, tendo em seu desfecho diversas visões diferentes do mesmo lugar.

Na última etapa, pertinente às intervenções espaciais que iriam ser passadas nos mesmos locais da etapa anterior, os alunos então tiveram que selecionar uma palavra que descrevesse como forma a representar tudo o que aconteceu e foi visto e sentido, na experiência vivida na etapa anterior, para poder dar continuação ao plano de atividades.

As execuções nesse momento são feitas em grupos que deveriam reunir as narrativas vivenciadas por eles para dar origem a uma nova narrativa que será a base predominante das produções em seguida. Até o momento de finalização deste trabalho apenas a turma A teve esse ofício completado.

Foi muito presente em todas as montagens dessa turma, a questão da amabilidade urbana que havia sido levada a debate em sala de aula. "Trata-se de um atributo espacial que se manifesta através de conexões e interações entre pessoas e espaço, opondo-se ao individualismo que por muitas vezes caracteriza as formas de convívio coletivo contemporâneas." (SANSÃO, 2012).

As intervenções espaciais foram muito focadas nas pessoas que compõem o Mercado da Produção, pois o mesmo parecia só ganhar vida através delas. As composições, entretanto possuíam caráter distinto, assim como suas formas de interação, temporalidades e transmissão de mensagens, como é possível ser visto nas figuras 4 e 5. 
Figura 4 - Intervenção de uma das equipes da turma A Fonte: Elaborado pelo autor, com base na pesquisa realizada, 2017.

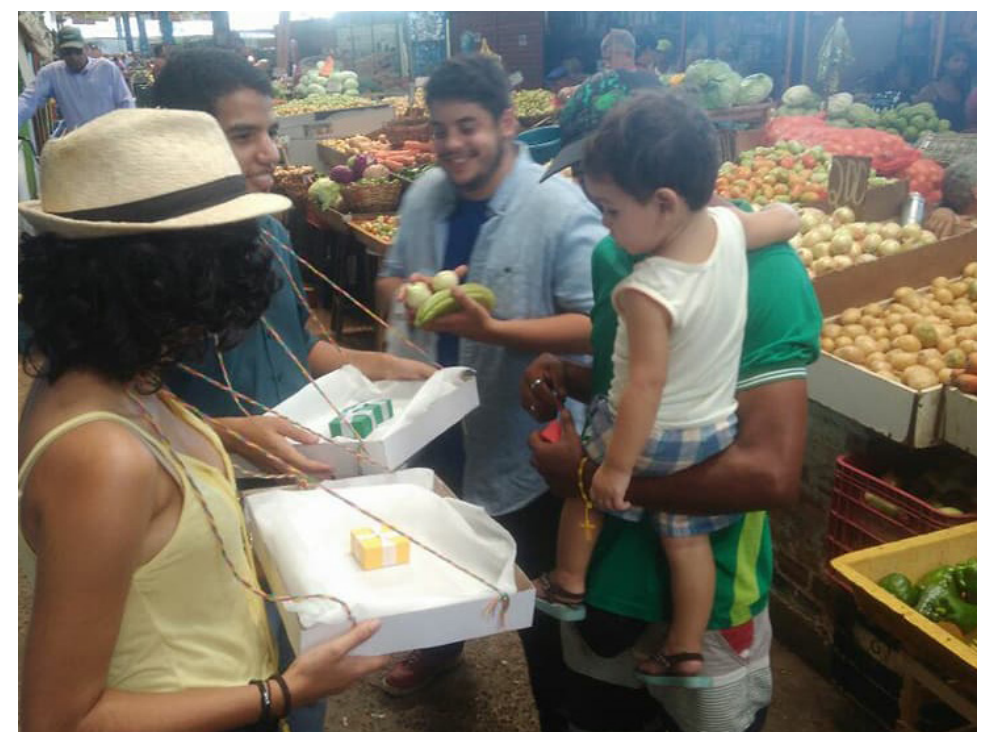

Figura 5 - Intervenção de uma das equipes da turma A Fonte: Elaborado pelo autor, com base na pesquisa realizada, 2017.

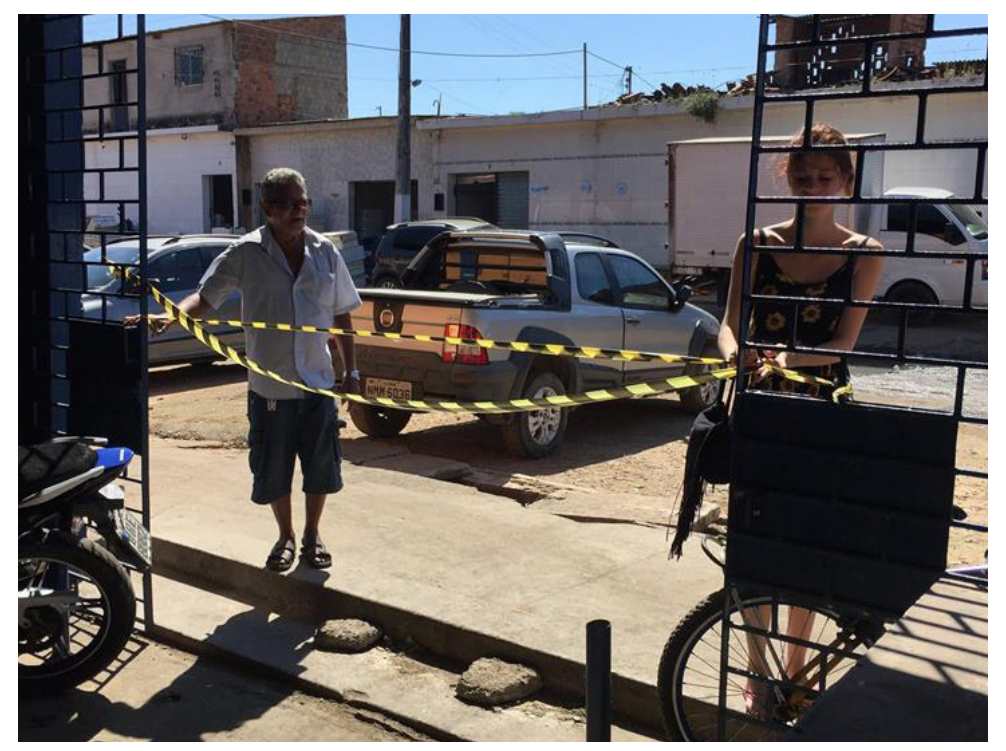

\section{CONSIDERAÇÕES FINAIS}

Pôde-se perceber de maneira significativa como o processo de verificação sendo feito em primeira pessoa, diretamente ligado com a experimentação e a proximidade com os espaços e as pessoas trazem uma perspectiva mais imersa, próxima e mais dedicada ao tocante das expressões espaciais, sendo resultante de melhores referências e conhecimentos, que levam a elaboração de um projeto mais concordante com o contexto que o envolve.

Com as três etapas que servem de base para as tarefas realizadas, os alunos são postos a disposição de situações novas e diferentes ao que se predispõem em suas práticas habituais, sendo em todas elas trabalhado constantemente com definições de expectativas e realidade, para que seja viável a percepção da disparidade das resoluções, quando em um momento partimos de conceitos imaginativos e suposições para quando possuímos propriedades efetivas e experiências sobre a situação.

Ao final, a oportunidade de avaliar duas turmas distintas permitiu constatar as diferenças, desde como cada turma direciona o trajeto da disciplina, uma vez que uma 
turma possui mais dificuldade de se desprender do literal e convencional e a outra turma compõe-se de forma mais conceitual e fantasiosa, como também o modo que o repertório de cada pessoa influencia nas coisas que serão percebidas, que irão chamar mais atenção, sendo assim, as experiências vividas como agente principal para as decisões tomadas.

Compreendendo por fim a necessidade de vivências, referências e um acervo de informações, onde nas ocasiões de estudo e apuração sobre a proposta de quaisquer eventuais projetos esses conhecimentos possam o aproximar às noções corpóreas, sensoriais e espaciais, itens necessários da prática projetual do designer.

\section{REFERÊNCIAS}

BERENSTEIN JACQUES, Paola. Corpografias urbanas. Arquitextos, n. 093.07. /São Paulo, Portal Vitruvius, fev. 2008.

\section{Paola. Elogio aos errantes. Breve histórico das errâncias}

urbanas. Arquitextos, n. 053. São Paulo, Portal Vitruvius, out. 2004.

DIDI-HUBERMAN, Georges. O que vemos, o que nos olha. São Paulo, Editora 34, 2010.

SANSÃO, Adriana. Amabilidade urbana: marcas das intervenções temporárias na cidade contemporânea. URBS. Revista de Estudios Urbanos y Ciencias Sociales, 2008.

Sobre os autores

Nathália Feitosa Barbosa (graduanda), UFAL < nathalia@tecdom.com.br>

Juliana Michaello Macedo Dias (doutora), UFAL < jumichaello@hotmail.com> 